\title{
Comparison of Toe Plantar Flexors Strength and Balancing Ability between Elderly Fallers and Non-fallers
}

\author{
Yong-Wook, Kim, MSc, PT ${ }^{1)}$, OH-Yun, Kwon, PhD, PT ${ }^{2)}$, HeOn-SeOck, Cynn, PhD, PT 2 , \\ Jong-Hyuck, WeOn, PhD, PT ${ }^{3)}$, Chung-Hwi YI, PhD, PT ${ }^{2)}$, TAE-Ho, KIM, PhD, PT $^{4}$ \\ 1) Department of Physical Therapy, College of Alternative Medicine, Jeonju University. \\ ${ }^{2)}$ Laboratory of Kinetic Ergocise Based on Movement Analysis, Dept. of Physical Therapy, College of \\ Health Science, Yonsei University: 234 Maeji-ri, Hungup-myon, Wonju-si, Kangwon-do, 220-710 South \\ Korea.TEL: +82 33-760-2721.FAX: +82 33-760-2496,E-mail:kwonoy@yonsei.ac.kr \\ 3) Department of Rehabilitation Medicine, Wonju Christian Hospital, Wonju College of Medicine, Yonsei \\ University \\ 4) Department of of Physical Therapy, Daegu Health College
}

\begin{abstract}
Purpose] We compared the differences in individual toe flexor muscle strength and balancing ability between elderly fallers and non-fallers and determined the correlation between individual toe flexor muscle strength and the functional reach test (FRT). [Subjects] Thirty community-dwelling older adults ( 15 fallers and 15 age- and sexmatched non-fallers) between 65 and 83 years of age participated in this study. [Method] Individual toe flexor muscle strength was measured using a dynamometer, and balance ability was assessed with the FRT, Berg balance scale, and a sensory organization test (SOT). [Results] The hallux and second toe flexor muscle strengths in the non-faller group were significantly stronger bilaterally than those in the faller group, whereas no significant differences in the third and fourth toe flexor muscle strengths were found. The individual toe plantar flexor muscle strengths were moderately correlated with FRT $(r=0.489-0.765)$. The non-faller group showed significantly greater balance ability in the FRT and SOT than the faller group. [Conclusion] The results of this study suggest that the force-generating capability of the hallux and second toe flexor muscle are related to the incidence of falls among elderly individuals.

Key words: Toe plantar flexors strength, Balance, Faller
\end{abstract}

(This article was submitted Jul. 14, 2010, and was accepted Aug. 23, 2010)

\section{INTRODUCTION}

Falls are defined as "events that result in a person coming to rest unintentionally on the ground or other lower level, not as the result of a major intrinsic event or overwhelming hazard"1). Fall injury is one of the major factors reducing the quality of the life of elderly people. One third of community-dwelling elderly people aged 65 years or over have reported falling at least twice a year ${ }^{2,3)}$. An elderly person who has experienced a fall worries about other accidents and feels less confident while performing physical and social activities ${ }^{4-6)}$. Accordingly, it is essential for elderly individuals to maintain their balance ability through postural control so that they can perform activities of daily living safely.

In order to maintain the center of gravity on the base of support while carrying on activities of daily living, it is necessary to integrate information from the visual, vestibular, and somatosensory systems. Information on body movements is perceived by the sensory systems, integrated by the central nervous system, and then passed on to the effector, the musculoskeletal system. Sufficient strength in the lower limb muscles is essential for maintaining static and dynamic balance. Many studies have considered muscle weakness in the lower limbs of elderly people as one of the major factors leading to fall accidents and injuries ${ }^{7-10)}$. The decline in muscle strength in the lower limbs with aging is responsible for balance impairment ${ }^{11)}$. Some studies have demonstrated that the muscle strength in the lower limbs of elderly individuals is highly correlated with their walking and balance ability ${ }^{12)}$. Chu et al. ${ }^{13)}$ reported that risk factors leading to injuries in falls were weakness of the lower limbs and unstable tandem walking.

Like the hip, knee, and ankle joints and surrounding muscles, the toes play an important role in maintaining stability during forward reach and forward propulsion during walking ${ }^{1,14)}$. Menz et al. ${ }^{14)}$ reported that the strength of the toe plantar flexor muscles was a significant independent predictor of the balance and functional abilities of elderly people. However, they measured the overall toe plantar flexor strength using a paper-grip test rather than individual toe plantar flexor muscles. Therefore, this study 
Table 1. General characteristics of participants

\begin{tabular}{lccrrc}
\hline \multirow{2}{*}{ Variables } & \multicolumn{2}{c}{ Fallers $(\mathrm{n}=15)$} & & \multicolumn{2}{c}{ Non-Fallers $(\mathrm{n}=15)$} \\
\cline { 2 - 3 } \cline { 5 - 6 } & Mean \pm SD & Range & & Mean \pm SD & Range \\
\hline Age (y) & $71.4 \pm 4.3$ & $66-81$ & & $72.1 \pm 5.0$ & $66-83$ \\
Height $(\mathrm{cm})$ & $156.3 \pm 5.4$ & $149-165$ & & $156.5 \pm 4.5$ & $149-164$ \\
Weight $(\mathrm{kg})$ & $61.3 \pm 7.5$ & $51-81$ & & $60.9 \pm 6.9$ & $48-78$ \\
\hline
\end{tabular}

Comparison between groups (Mann-Whitney U test).

compared the toe strength and balance ability of elderly fallers and non-fallers using objective methods and determined the correlations between individual toe plantar flexor strengths and the results of the functional reach test (FRT). Three hypotheses were tested in this study: 1) toe plantar flexor strength would not differ significantly between elderly fallers and non-fallers; 2) the balance test would not differ significantly between elderly fallers and non-fallers; and 3) no significant correlation would be found between individual toe plantar flexor strengths and the FRT.

\section{SUBJECTS AND METHODS}

\section{Subjects}

The participants were recruited from among communitydwelling volunteers. Thirty subjects between 65 and 83 years of age met the inclusion criteria. The principal investigator asked each subject about his or her history of falls during the screening test. Fifteen persons ( 7 males and 8 females) who had fallen at least once while walking during the previous 12 months were included in faller group ${ }^{15-17)}$; the non-faller group included 15 age- and sex-matched persons. A fall was not counted if it occurred due to dizziness, illness, during unusual activities in a hazardous environment. In the faller group, eleven subjects (73.3\%) recalled falling 3 or more times, and 4 subjects $(26.7 \%)$ recalled falling 1 or 2 times in the year prior to the study. No significant differences between the two groups in terms of age, height, or weight were found (Table 1).

The following subjects were excluded: (1) subjects who required aids to walk independently, (2) those with severe musculoskeletal disorders or foot and toe deformities that interfered with walking, (3) subjects with neurological impairments or vestibular dysfunction interfering with balance diagnosed by an neurotologist based on vertical axis rotation, positional, and oculomotor testing ${ }^{18)}$, (4) subjects with orthostatic hypotension, (5) subjects with significant cognitive dysfunction who had difficulty understanding instructions (cognitive impairment was defined as a score of 24 or below on the Mini-Mental State Examination) ${ }^{19}$, (6) subjects taking medications that affected their balance ability, and (7) subjects with sensory impairment or diabetic peripheral neuropathy in the lower limbs. All participants signed an informed consent form after receiving a full explanation of the purpose of this study. The institutional review board of Yonsei University approved this study.

\section{Methods}

Individual toe plantar flexor muscle strengths were measured using a digital dynamometer (MSC-200, AMETEC Inc, FL, USA). A wooden frame consisting of a platform $(20 \times 3 \times 2.3 \mathrm{~cm}$ width $\times$ length $\times$ height $)$ and a vertical board $(7.7 \times 7.7 \times 4.4 \mathrm{~cm}$ width $\times$ length $\times$ height $)$ was constructed. A foot board $(40 \times 27 \times 5 \mathrm{~cm}$ width $\times$ length $\times$ height) was used to position the foot and toes to be tested, and the digital dynamometer was attached to the vertical board. The height of the dynamometer could be adjusted using a longitudinal slot in which it was fastened by bolts and nuts to accommodate individual variations in toe and foot dimensions. A thin leather strap ( $1.5 \mathrm{~cm}$ wide) was attached to the hook on the digital dynamometer. This device was previously determined to have high intra-rater reliability for the 2 nd to 4 th toes (intraclass correlation coefficient $($ ICC $)=0.88-0.96)^{20)}$.

The subject was instructed to sit comfortably with his or her back supported by the chair backrest and to put the foot to be tested on the foot board. The hip, knee, and ankle joints were all positioned at 90 degrees during the test procedure. The toe to be measured was inserted into a leather cuff, which was positioned on the plantar side of the proximal phalanx of the toe to be tested. The subject was instructed to push the leather cuff downward with the toe to be tested as hard as possible ${ }^{21)}$. Each subject practiced three times before the measurement to become familiar with the testing procedures. The maximum strength of each toe plantar flexor muscle was determined during a 5-second push-down period. The unit of strength measurement was the kilogram $(\mathrm{kg})$. The mean of three trials was calculated for use in the data analysis. Subjects had a 3-minute rest between trials to minimize muscle fatigue. An independent physical therapist with experience working with a digital dynamometer read and recorded the strength value of each toe plantar flexor muscle on the digital display to eliminate experimental bias.

A yardstick was mounted horizontally on a wall for the functional reach test. The subject was instructed to stretch the dominant upper limb forward with the shoulders kept at 90 degrees flexion, with the arm held horizontal while maintaining a fixed base of support to test the limits of stability in the anterior direction ${ }^{21)}$. The distance in centimeters was measured from the tip of the third metacarpal of the subject's clenched fist knuckle in the standing position. Then, the subject reached forward as far as possible without losing balance and the measurement was repeated. A second investigator stood by to ensure the subject's safety during the FRT. The mean of three trials was calculated for the data analysis. The ICC of the testretest reliability of the FRT was 0.92 , and the ICC for intertester reliability was $0.98^{21)}$. 
The standardized Berg balance scale (BBS) proposed by Berg et al. ${ }^{22)}$ was measured. The balance is evaluated using the sum of 14 tasks scores. The ICCs for the inter- and intrarater reliability were 0.98 and 0.99 , respectively, in a previous study ${ }^{22)}$.

The sensory organization test (SOT) was performed using the NeuroCom Smart Balance Master system (NeuroCom International Inc, Clackamas, OR, USA). The subject wore a harness for safety. The upper limbs were positioned naturally at the side of body, the feet were positioned along parallel lines on the plate, and the subject was instructed not to move the feet during the test. The SOT consists of six sensory conditions tested in a standard $\operatorname{order}^{23)}: 1$ ) normal vision and support surface; 2) eyes closed and normal support surface; 3 ) sway-referenced vision and normal support surface; 4) normal vision and sway-referenced support surface; 5) eyes closed and sway-referenced support surface; and 6) sway-referenced vision and support surface. The average of the six tests was taken as a composite equilibrium score for use in the data analysis. The SOT composite score showed good test-retest reliability, with an ICC of 0.66 in a previous study ${ }^{24)}$.

The data were analyzed using SPSS version 17.0 (Chicago, IL, USA) for Windows. The Mann-Whitney U test was used to determine the statistical differences in the measured values for the demographic data and the three balance tests between the faller and non-faller groups. To determine the intra-tester reliability of individual toe plantar flexor strengths measured using the digital force dynamometer, the ICC was calculated ${ }^{25)}$. The test and retest were performed within 5 days. The correlation coefficients between toe plantar flexor muscle strengths and the FRT were calculated.

\section{RESULTS}

In our study, the intra-tester reliability for the toe plantar flexor muscle strength measurements was high (ICC values 0.89-0.95) (Table 2).

Table 3 shows the mean, standard deviation, and range for the measured toe plantar flexor muscles. The plantar flexor strengths of the hallux and second toe on both sides was significantly lower in the faller group than in the nonfaller group $(p<0.01$ and $p<0.01)$. However, no significant differences in the strengths of the toe plantar flexors of the third and fourth toes were found between the two groups.

The results of the three balance measures are shown in Table 4. No significant difference was seen between the faller and non-faller groups in terms of the BBS, whereas the FRT $(22.87 \pm 4.50 \mathrm{~cm}$ vs. $28.00 \pm 5.49 \mathrm{~cm})$ and SOT score $(70.60 \pm 7.34 \%$ vs. $75.80 \pm 5.65 \%)$ of the faller group were significantly lower than those of the non-faller group.

The correlation coefficients between the toe plantar flexor muscle strength and FRT ranged from $0.489(\mathrm{p}<0.01)$ to $0.765(\mathrm{p}<0.01)($ Table 5).

\section{DISCUSSION}

We investigated whether differences in individual toe
Table 2. Intra-tester reliability of the toe plantar flexor muscle strength measurements using a digital dynamometer

\begin{tabular}{lcc}
\hline Variable & ICCs $(1,1)$ & $95 \%$ CI \\
\hline Hallux & 0.89 & $0.67-0.97$ \\
$2^{\text {nd }}$ toe & 0.91 & $0.74-0.97$ \\
$3^{\text {rd }}$ toe & 0.95 & $0.85-0.99$ \\
$4^{\text {th }}$ toe & 0.90 & $0.70-0.97$ \\
\hline
\end{tabular}

Abbreviations; ICCs: intraclass correlation coefficients. CI: confidence interval.

plantar flexor muscle strengths and balance ability exist between fallers and age- and sex-matched non-fallers. The toe plantar flexor muscles of the hallux and second toes in the non-faller group were significantly stronger than in the faller group bilaterally, whereas no significant difference in the third or fourth toe plantar flexor strengths was seen between the two groups. The non-faller group had significantly better balance scores in the FRT and SOT than the faller group.

Our findings show that non-fallers had significantly greater toe plantar flexor muscle strength $(p<0.01)$ than the fallers in the hallux and second toes of both feet, whereas no significant differences were seen for the third or fourth toes. Previous research using a pressure platform showed that older people had $32 \%$ less plantar flexion strength of the hallux and $27 \%$ less plantar flexion strength of the lesser toes than younger people ${ }^{14)}$. Toe flexor muscle strength decreases significantly with age ${ }^{26)}$. Previous studies have compared toe plantar flexor strength between older and younger persons. Daubney and Culham ${ }^{15)}$ reported significantly stronger hip extensors and ankle dorsiflexors in elderly non-fallers compared to fallers. Ours is the first study to compare the toe plantar flexor strength between fallers and non-fallers measuring individual toe plantar flexor strengths. Fong et al. ${ }^{27)}$ found a significantly increased peak pressure $(30 \%)$ and pressure-time integral $(79 \%)$ in the hallux on a slippery surface compared to a nonslippery surface. They suggested that greater toe grip is a strategy for adapting to slippery surfaces. In our study, the plantar flexor muscle strength of the hallux was greater in the non-faller group than in the faller group, indicating the importance of the medial part of the toe plantar flexors in maintaining balance. Elderly people tend to fall on relatively slippery surfaces, and many possible causes exist for falling among elderly people. The weakness of the medial toe flexors may be a factor contributing to falls in elderly individuals. The function of the hallux is to control balance and to provide forward propulsion during walking and running. If the hallux plantar flexor becomes weak with aging, it could affect static or dynamic balance ability.

It is not clear whether weakness in the hallux and second toe results in falling or, alternatively, fear of falling causes disuse atrophy of the hallux and second toe. A previous study showed that an old person who has experienced falls faces limits to normal physical activities, like walking, due to fear of injuries related to falls ${ }^{6}$, and the difference in the toe muscle strength between the two subgroups seen in our 
Table 3. Comparison of toe flexor muscle force measurements

\begin{tabular}{|c|c|c|c|c|}
\hline \multirow{2}{*}{ Variables (Kg) } & \multicolumn{2}{|c|}{ Fallers $(n=15)$} & \multicolumn{2}{|c|}{ Non-fallers $(n=15)$} \\
\hline & Mean \pm SD & Range & Mean \pm SD & Range \\
\hline Right Hallux & $4.67 \pm 1.64$ & $2.29-7.31$ & $7.02 \pm 1.10^{* *}$ & $5.16-9.40$ \\
\hline Left Hallux & $4.34 \pm 1.37$ & $2.19-6.19$ & $6.97 \pm 1.30^{* *}$ & $5.46-9.71$ \\
\hline Right $2^{\text {nd }}$ toe & $3.07 \pm 1.21$ & $1.13-5.27$ & $4.77 \pm 0.98^{* *}$ & $3.06-6.40$ \\
\hline Left $2^{\text {nd }}$ toe & $3.04 \pm 1.17$ & $1.29-5.22$ & $4.68 \pm 1.00^{* *}$ & $3.11-6.44$ \\
\hline Right $3^{\text {rd }}$ toe & $2.74 \pm 1.08$ & $1.16-4.36$ & $3.33 \pm 0.76$ & $2.19-4.54$ \\
\hline Left $3^{\text {rd }}$ toe & $2.74 \pm 1.07$ & $1.03-4.32$ & $3.34 \pm 0.64$ & $2.34-4.50$ \\
\hline Right $4^{\text {th }}$ toe & $2.38 \pm 1.02$ & $0.79-3.96$ & $2.87 \pm 0.73$ & $1.81-4.21$ \\
\hline Left $4^{\text {th }}$ toe & $2.24 \pm 0.92$ & $0.92-3.70$ & $2.76 \pm 0.94$ & $1.26-4.13$ \\
\hline
\end{tabular}

Comparison between groups (Mann-Whitney $\mathrm{U}$ test with the Bonferroni correction). ${ }^{*} \mathrm{p}<0.01$.

Table 4. Descriptive characteristics of subjects and balance measures

\begin{tabular}{llrlll}
\hline \multirow{2}{*}{ Variables } & \multicolumn{2}{c}{ Fallers $(\mathrm{n}=15)$} & & \multicolumn{2}{c}{ Non-fallers $(\mathrm{n}=15)$} \\
\cline { 2 - 3 } \cline { 5 - 6 } & Mean \pm SD & Range & & Mean \pm SD & Range \\
\hline FRT (cm) & $22.87 \pm 4.50$ & $13-30$ & & $28.00 \pm 5.49^{* *}$ & $22-45$ \\
BBS (score) & $52.33 \pm 3.46$ & $45-56$ & & $53.40 \pm 1.64$ & $50-56$ \\
SOT (score) & $70.60 \pm 7.34$ & $5-81$ & & $75.80 \pm 5.65^{*}$ & $67-86$ \\
\hline
\end{tabular}

Abbreviations: FRT, functional reach test; BBS, Berg balance scale (maximal score $=56$ ); SOT, sensory organization test. Comparison between groups (Mann-Whitney U test). ${ }^{*} \mathrm{p}<0.05$, $* * \mathrm{p}<0.01$.

Table 5. Correlation between toe plantar flexors muscle strength and FRT

\begin{tabular}{llllllllll}
\hline & \multicolumn{4}{c}{ Right } & & \multicolumn{3}{c}{ Left } \\
\cline { 2 - 4 } \cline { 6 - 8 } & Hallux & $2^{\text {nd }}$ & $3^{\text {rd }}$ & $4^{\text {th }}$ & & Hallux & $2^{\text {nd }}$ & $3^{\text {rd }}$ & $4^{\text {th }}$ \\
\hline FRT & $0.765^{* *}$ & $0.693^{* *}$ & $0.658^{* *}$ & $0.611^{* *}$ & & $0.636^{* *}$ & $0.564^{* *}$ & $0.534^{* *}$ & $0.489 * *$ \\
\hline
\end{tabular}

Abbreviations: FRT, functional reach test. $* * \mathrm{p}<0.01$.

study is most likely attributable to this.

No validated measures for individual toe plantar flexor strengths are available. A manual muscle-testing method is commonly used to measure strength in the clinical setting ${ }^{28)}$. However, this method does not measure toe strength quantitatively. Many researchers have tried to measure toe strength quantitatively. Endo et al. ${ }^{26)}$ and Mickle et al. ${ }^{29)}$ used a force plate to determine the ground reaction force, and Menz et al. ${ }^{14)}$ and Nihal et al. ${ }^{30)}$ used a pressure sensor and a paper-grip test to estimate toe strength. Other researchers have measured the total toe flexor muscle strength using a dynamometer ${ }^{31,32)}$. Fong et al. ${ }^{27)}$ calculated toe strength using a pressure insole system and emphasized toe grip strength. Kwon et al. ${ }^{20)}$ used a dynamometer to measure the strength of toes 2-4 individually and reported high test-retest reliability. In our study, the intra-tester reliability for these measures on two separate occasions was also high ( $\mathrm{ICC}=0.89-0.95)$. It is possible that strength measurement with a digital dynamometer can be used clinically to measure toe strength of the elderly.

In this study, the average distance measured in the FRT was significantly lower in the faller group than that in the non-faller group ( 22.87 vs. $28.00 \mathrm{~cm}$, respectively). O'Brien et al. ${ }^{16)}$ reported similar results in that female elderly fallers had a significantly lower average score on the FRT (22.2 vs. $27.7 \mathrm{~cm}$ for fallers and non-fallers, respectively). This is consistent with our result. Some studies found that toe plantar flexor strength was related to the FRT value. Endo et $\mathrm{al}^{26)}$ reported a correlation between the toe flexor isometric muscle strength and the functional toe length as a functional reach task, which was defined as the 'maximum distance that the subject could move the center of ground reaction force forward of the first metatarsophalangeal joint'. Kozak et al. ${ }^{33)}$ also stated that greater toe flexor muscle strength will increase the force under the distal phalanx of each toe, especially the long toes, so that the center of pressure can be moved toward the metatarsophalangeal joint. We examined whether individual toe strength was correlated with FRT and found that individual toe plantar flexor muscle strengths and FRT were moderately correlated $(r=0.489-0.765)$. The correlation was greater for the hallux and second toe than for the third and fourth toes. These results suggest that hallux and second toe plantar flexor muscle strengths contribute to the FRT result of the elderly.

The SOT assesses a person's ability to maintain balance under altered sensory conditions by relying on available sensory input and suppressing misleading input ${ }^{34)}$. Wallmann ${ }^{17)}$ found significantly different SOT scores 
between 10 fallers and 15 non-fallers who were at least 60 years of age. In our study, the SOT score was significantly lower in the faller group $(70.60 \pm 7.34 \%)$ than in the nonfaller group $(75.80 \pm 5.65 \%)$. This indicates that the balance ability of the faller group was lower than that of the nonfaller group. In contrast, one study reported no significant difference in SOT scores between fallers and non-fallers ${ }^{35}$. This difference in results may have arisen from differences in the characteristics of the participants, definition of fallers, and different measurement methods used. Therefore, further studies are needed to clarify whether the SOT score has the ability to distinguish between fallers and non-fallers.

In our study, no significant difference in BBS score was found between the faller and non-faller groups. In other studies of community-dwelling older adults, the BBS was not found to be a good predictor of falls ${ }^{36,37)}$. The BBS is not sensitive enough to uncover factors that contributed to falls in older adults who are active ${ }^{38)}$. Boulgarides et al. ${ }^{38)}$ found no significant difference between groups, concurring with our findings. O'Brien et al. ${ }^{37)}$ found that the BBS was less sensitive for predicting falls by community-dwelling older people who were in good health than in residents of the nursing home studied by Berg et al. ${ }^{39)}$ Our subjects were community dwellers, which is one possible reason that no significant difference in the BBS score was found between the faller and non-faller groups.

Our study has several limitations. First, we did not control for psychological confounding variables such as anxiety and fear of falling during the test. Second, our sample size was too small to generalize our findings to all community-dwelling fallers. Third, the history of falling depended on the subject's memory, and recall bias can influence results. Fourth, although age- and sex-matched subjects participated in this study, other factors potentially affecting balance were not matched between the two groups. Further studies are needed to determine whether toe plantar flexor strengthening exercises can improve balancing ability in the elderly population.

\section{ACKNOWLEDGEMENT}

This study was supported by the Korea Research Foundation Grant funded by the Korea Government (MEST, Basic Research Promotion Fund).

\section{REFERENCES}

1) Menz HB, Morris ME, Lord SR: Foot and ankle risk factors for falls in older people: a prospective study. J Gerontol A Biol Sci Med Sci, 2006, 61: 866870 .

2) Hausdorff JM, Rios DA, Edelberg HK: Gait variability and fall risk in community-living older adults: a 1-year prospective study. Arch Phys Med Rehabil, 2001, 82: 1050-1056.

3) Hornbrook MC, Stevens VJ, Wingfield DJ, et al.: Preventing falls among community-dwelling older persons: results from a randomized trial. Gerontologist, 1994, 34: 16-23.

4) Nevitt MC, Cummings SR, Kidd S, et al.: Risk factors for recurrent nonsyncopal falls: a prospective study. JAMA, 1989, 261: 2663-2668.

5) O'Loughlin JL, Robitalille Y, Boivin JF, et al.: Incidence of and risk factors for falls and injurious falls among the community-dwelling elderly. Am J Epidemiol, 1993, 137: 342-354.

6) Tinetti ME, Mendes de Leon CF, Doucette JT, et al.: Fear of falling and fallrelated efficacy in relationship to functioning among community-living elders. J Gerontol, 1994, 49: M140-M147.

7) Brauer SG, Burns YR, Galley P: A prospective study of laboratory and clinical measures of postural stability to predict community-dwelling fallers. J Gerontol A Biol Sci Med Sci, 2000, 55: M469-M476.

8) Guralnik JM, Ferrucci L, Simonsick EM, et al.: Lower-extremity function in persons over the age of 70 years as a predictor of subsequent disability. N Engl J Med, 1995, 332: 556-561.

9) Menz HB, Morris ME, Lord SR: Foot and ankle characteristics associated with impaired balance and functional ability in older people. J Gerontol A Biol Sci Med Sci, 2005, 60: 1546-1552.

10) Tinetti ME: Factors associated with serious injury during falls by ambulatory nursing home residents. J Am Geriatr Soc, 1987, 35: 644-648.

11) Horak FB, Shupert CL, Mirka A: Components of postural dyscontrol in the elderly: a review. Neurobiol Aging, 1989, 10: 727-738.

12) Wolfson L, Judge J, Whipple R, et al.: Strength is a major factor in balance, gait and the occurrence of falls. J Gerontol A Biol Sci Med Sci, 1995, 50: 6467.

13) Chu LW, Pei CK, Chiu A, et al.: Risk factors for falls in hospitalized older medical patients. J Gerontol A Biol Sci Med Sci, 1999, 54: M38-M43.

14) Menz HB, Zammit GV, Munteanu SE, et al.: Plantarflexion strength of the toes: age and gender differences and evaluation of a clinical screening test. Foot Ankle Int, 2006, 27: 1103-1108.

15) Daubney ME, Culham EG: Lower-extremity muscle force and balance performance in adults aged 65 years and older. Phys Ther, 1999, 79: 11771185.

16) O'Brien K, Culham E, Pickles B: Balance and skeletal alignment in a group of elderly female fallers and nonfallers. J Gerontol A Biol Sci Med Sci, 1997, 52: B221-B226.

17) Wallmann HW: Comparison of elderly nonfallers and fallers on performance measures of functional reach, sensory organization, and limits of stability. $\mathrm{J}$ Gerontol A Biol Sci Med Sci, 2001, 56: M580-M583.

18) Wuyts FL, Furman J, Vanspauwen R, et al.: Vestibular function testing. Curr Opin Neurol, 2007, 20: 19-24.

19) Folstein MF, Folstein SE, McHugh PR: Mini-Mental State Examination: a practical method for grading the cognitive state of patients for the clinician. J Psychiatr Res, 1975, 12: 189-198.

20) Kwon OY, Tuttle LJ, Johnson JE, et al.: Muscle imbalance and reduced ankle joint motion in people with hammer toe deformity. Clin Biomech, 2009, 24: 670-675.

21) Duncan PW, Weiner DK, Chandler J, et al.: Functional reach: a new clinical measure of balance. J Gerontol, 1990, 45: M192-M197.

22) Berg KO, Wood-Dauphinee SL, Williams JI, et al.: Measuring balance in the elderly: Preliminary development of an instrument. Physiotherapy Canada, 1989, 41: 304-311.

23) Nashner LM: Computerized dynamic posturography. In: Handbook of balance function testing. St. Louis: Mosby-Year Book, 1993, pp 208-307.

24) Ford-Smith CD, Wyman JF, Elswick RK Jr, et al.: Test-retest reliability of the sensory organization test in noninstitutionalized older adults. Arch Phys Med Rehabil, 1995, 76: 77-81.

25) Krebs DE: Computer communication. Phys Ther, 1984, 64: 1581-1582.

26) Endo M, Ashton-Miller JA, Alexander NB: Effects of age and gender on toe flexor muscle strength. J Gerontol A Biol Sci Med Sci, 2002, 57: M392M397.

27) Fong DT, Mao DW, Li JX, et al.: Greater toe grip and gentler heel strike are the strategies to adapt to slippery surface. J Biomech, 2008, 41: 838-844.

28) Lin HT, Hsu AT, Chang JH, et al.: Comparison of EMG activity between maximal manual muscle testing and cybex maximal isometric testing of the quadriceps femoris. J Formos Med Assoc, 2008, 107: 175-180.

29) Mickle KJ, Munro BJ, Lord SR, et al.: Toe weakness and deformity increase the risk of fall in older people. Clin Biomech, 2009, 24: 787-791.

30) Nihal A, Goldstein J, Haas J, et al.: Toe flexor force in dancers and nondancers. Foot Ankle Int, 2002, 23: 1119-1123.

31) Senda M, Takahara Y, Yagata Y, et al.: Measurement of the muscle power of the toes in female marathon runners using a toe dynamometer. Acta Med Okayama, 1999, 53:189-191.

32) Goodall RM, Hammes MR: Electronic comparison of toe strengths for diagnosis of lumbar nerve root lesions. Med Biol Eng Comput, 1986, 24: 555557.

33) Kozak K, Ashton-Miller JA, Alexander NB: The effect of age and movement speed on maximum forward reach from an elevated surface: a study in healthy women. Clin Biomech, 2003, 18: 190-196.

34) Tang PF, Moore S, Woollacott MH: Correlation between two clinical balance measures in older adults: functional mobility and sensory organization test. J Gerontol A Biol Sci Med Sci, 1998, 53: M140-M146.

35) Anacker SL, Di Fabio RP: Influence of sensory inputs on standing balance in community-dwelling elders with a recent history of falling. Phys Ther, 1992, 
72: $575-584$.

36) Bogle Thorbahn LD, Newton RA: Use of the Berg Balance Test to predict falls in elderly persons. Phys Ther, 1996, 76: 576-785.

37) O'Brien K, Pickles B, Culham E: Clinical measures of balance in communitydwelling elderly female fallers and non-fallers. Physiotherapy Canada, 1998, 212-221.
38) Boulgarides LK, McGinty SM, Willett JA, et al.: Use of clinical and impairment-based tests to predict falls by community-dwelling older adults. Phys Ther, 2003, 83: 328-339.

39) Berg KO, Wood-Dauphinee SL, Williams JI, et al.: Measuring balance in the elderly: validation of an instruments. Can J Public Health, 1992, 83: S7-S11. 